\title{
Role of human papillomavirus in determining the HLA associated risk of cervical carcinogenesis
}

Nuffield Department of Pathology and Bacteriology, University of Oxford, John Radcliffe Hospital, Oxford OX3 9DU

W Z Mehal

Y-M D Lo

C S Herrington

$M$ F Evans

J O'D McGee

K A Fleming

The Medical School

M C Papadopoulos

Molecular Oncology

Laboratory, ICRF

Clinical Oncology

Unit Institute of

Molecular Medicine

K Odunsi

T S Ganesar

Nuffield Department of Clinical Medicine J I Bell

Correspondence to: Dr K A Fleming

Accepted for publication 26 April 1994

W Z Mehal, Y-M D Lo, C S Herrington, M F Evans, M C Papadopoulos, K Odunsi, T S Ganesan, J O'D McGee, J I Bell, K A Fleming

\begin{abstract}
Aims-To investigate the role of human papillomavirus (HPV) in the association between HLA DQw3 and squamous cell cancer of the cervix (SCCC).

Methods-Tissue from 194 cervical samples, ranging from normal, through cervical intraepithelial neoplasia, to SCCC, were typed for HPV by amplification of the $\mathrm{L} 1$ gene using degenerate consensus primers, followed by oligonucleotide probing. HLA DQw3 typing was undertaken in the same samples using a new PCR amplification system using primers common to all DQ loci, followed by restriction digestion with $M l u 1$ to differentiate HLA DQw3 types-null, heterozygous, and homozygous. The data were analysed using $\chi^{2}$ analysis and by calculating relative risks with the $95 \%$ confidence interval.

Results-Samples $(\mathrm{n}=188)$ were successfully typed for HPV and 177 were typed for HLA DQw3. There was a nonsignificant rise in the prevalence of HLA DQw3 in SCCC $(64 \cdot 3 \%)$ compared with the group with normal histology $(53 \cdot 2 \%)$. Analysis of the prevalence of HLA DQw3 on the basis of HPV infection rather than histology showed that 63 of $95(66.3 \%)$ of the HPV positive samples contained HLA DQw3 alleles, compared with 39 of 78 $(50 \cdot 0 \%)$ of the HPV negative samples $\left(\chi^{2}\right.$ 4.06; $\mathrm{p}<0.05$ ).

Conclusions-There was a significant association between HLA DQw3 and cervical HPV infection. This may be because people with HLA DQw3 are less able to mount an effective immune response to HPV, which predisposes them to the development of SCCC.
\end{abstract}

(F Clin Pathol 1994;47:1077-1081)

Squamous cell cancer of the cervix (SCCC) accounts for over 450000 new cases annually. ${ }^{1}$ The epidemiology of SCCC has been extensively studied. ${ }^{2}$ Early age at first sexual intercourse and multiple sexual partners have been established as independent risk factors for this disease. ${ }^{34}$ These associations suggest that a sexually transmitted agent may have a role in the development of SCCC, and this is corroborated by studies showing a higher number of sexual partners for husbands of patients with SCCC, compared with healthy people,${ }^{5}$ and evidence for the clustering of cervical and penile cancer. ${ }^{6}$

Herpes simplex virus (HSV) and human papillomavirus (HPV) have both been implicated as infectious agents involved in cervical carcinogenesis. $^{2}$ Case control studies have shown a significantly higher incidence of antibodies to HSV in cases than controls, but whether this effect is secondary to the greater number of sexual partners among the cases of SCCC is controversial. ${ }^{78}$

Papillomaviruses cause benign warts, and Franceschi et al showed that patients with genital warts were more likely to have cervical dyskaryosis than women with trichomoniasis or gonorrhoea. ${ }^{9}$ Since this report, HPV has been detected in $75-100 \%$ of SCCC cases, depending on the methoo used ${ }^{1011}$; the strongest associations are for certain "high risk" HPV subtypes (HPV 16, 18, 31, 33, 35). ${ }^{12}$ The incidence of high risk HPV types in cervical tissue increases with increasing dysplasia of the cervical epithelium, ${ }^{13}$ but it is clear that HPV infection is not the only factor in the development of cervical cancer. Between 10 and $20 \%$ of women without cervical abnormalities have cervical infection with "high risk" HPV subtypes, ${ }^{14}{ }^{15}$ and a proportion of women with cervical dysplasia and HPV spontaneously revert to normal histology, while some progress to SCCC. ${ }^{16}$

Recently, an increased prevalence of HLA DQw3 was demonstrated in a group of patients with SCCC, compared with a normal population. ${ }^{17}$ As the HLA system is known to have an important role in viral clearance ${ }^{18}$ and may be involved in possible immune surveillance against certain neoplasms, ${ }^{19}$ the association between DQw3 and SCCC could be a result of DQw3 positive subjects having either (a) a relative inability to clear HPV infection; or (b) a relative inability to provide immune surveillance against dysplastic tissue.

To investigate these possibilities, we developed a rapid system for DQw3 typing based on primer directed mutagenesis and restriction digestion.

\section{Methods}

One hundred and sixty six cervical smears showing the cytological changes of dysplasia and 28 formalin fixed, paraffin wax embedded cervical cancers taken between 1988 and 1989 were available for study. Punch biopsy specimens were available for 140 of the 166 cases for histological staging of dysplasia 
Cervical histology, HLA DQw3, and HPV status

\begin{tabular}{llll}
\hline Cervical histology & HLA DQw3 positive & HPV positive \\
\hline Normal & $\mathrm{n}=73$ & $33 / 62(53 \cdot 2 \%)$ & $26 / 71(36 \cdot 6 \%)$ \\
CIN I & $\mathrm{n}=27$ & $15 / 26(57 \cdot 7 \%)$ & $10 / 27(37 \cdot 0 \%)$ \\
CIN II & $\mathrm{n}=15$ & $8 / 15(53 \cdot 3 \%)$ & $12 / 15(80 \cdot 0 \%)$ \\
CIN III & $\mathrm{n}=24$ & $12 / 21(57 \cdot 1 \%)$ & $21 / 22(95 \cdot 5 \%)$ \\
SCCC & $\mathrm{n}=28$ & $18 / 28(64 \cdot 3 \%)$ & $26 / 28(92 \cdot 9 \%)$ \\
\hline
\end{tabular}

(cervical intraepithelial neoplasia (CIN) I to III). Sixty local people who were being considered as renal donors were used as normal controls.

Histological classification into the four groups of normal, CIN I, CIN II, CIN III and SCCC was carried out using established criteria. ${ }^{20}$ The histological diagnoses are shown in the table. Of the 28 carcinomas, nine were well differentiated (large cell keratinising), 12 were moderately differentiated (large cell focally keratinising), four were papillary carcinomas, and three were poorly differentiated (two large cell non-keratinising and one small cell non-keratinising).

The CIN system was chosen in favour of the Bethesda system of classification of squamous intraepithelial lesions because it would permit direct comparison and discussion of our results with the other published studies.

All DQw3 alleles possess an $A$ at the last base of codon 38 (fig 1). Codons 39 and 40 are, respectively, CGC and TTC. Thus if the first base of codon 40 can be mutated to a $\mathrm{G}$, then a MluI site will be created for the DQw3 alleles. The non-DQw3 alleles, on the other hand, possess a $G$ in the last base of codon 38 . No MluI site will therefore be created by mutating the first base of codon 40. An upstream primer $\mathrm{DB} 130^{22}$ is used in conjunc-
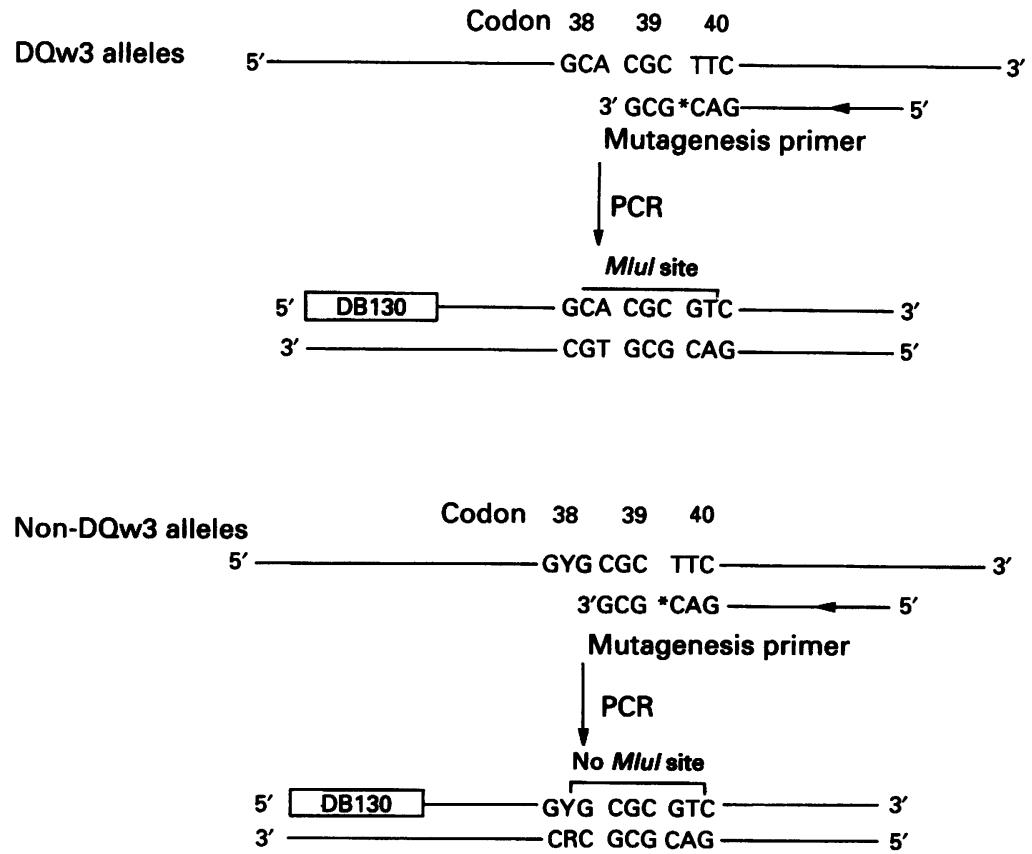

Figure 1 Principles of $D Q w 3$ typing system. PCR was carried out using an upstream primer DB130 and a downstream mutagenesis primer. ${ }^{*}$ The artificial mismatch was introduced to mutate the template, so as to create a MluI site (ACGCGT) for DOw3 alleles. $Y=T$ or $C ; R=A$ or $G$ (IUPAC nomenclature). tion with this mutagenesis primer (the mutating base is underlined).

Primer sequences are:

Mutagenesis primer: ${ }^{5} \mathrm{CCG}$ GTA CAC CCC CAC GTC GCT GTC GAC GCG ${ }^{3 !}$

DB130: "AGG GAT CCC CGC AGA GGA TTT CGT GTA CC ${ }^{3 \prime}$.

PCR was carried out as described ${ }^{23}$ in $100 \mu \mathrm{l}$ reaction volumes. Thermal cycling was carried out using a Biometra TRIO thermoblock. The thermal profile was an initial denaturation at $94^{\circ} \mathrm{C}$ for eight minutes, followed by cycling at $94^{\circ} \mathrm{C}$ for one minute, $60^{\circ} \mathrm{C}$ for one minute, and $72^{\circ} \mathrm{C}$ for one minute, and a final extension at $72^{\circ} \mathrm{C}$ for eight minutes. Twenty five, 30 , and 40 cycles were carried out for DNA extracted from peripheral blood, cervical smears, and paraffin wax embedded cervical tissue, respectively.

After amplification, $10 \mu \mathrm{l}$ of the PCR products were restricted in the presence of 50 units of MluI (Boehringer Mannheim, Germany) in a total volume of $20 \mu \mathrm{l}$ using the buffer provided by the manufacturer. Restriction was allowed to proceed overnight (for about 12 hours) at $37^{\circ} \mathrm{C}$.

After restriction, the products were analysed by electrophoresis in $1.5 \%$ agarose gels. Visualisation of the products was performed under ultraviolet transillumination.

For PCR, genomic DNA was extracted from venous blood using a standard protocol with proteinase $\mathrm{K}$ digestion, followed by phenol/chloroform extraction. ${ }^{24}$ Formalin fixed, paraffin wax embedded tissue sections were cut to a thickness of $5 \mu \mathrm{m}$, to obtain a total tissue volume of $2 \mathrm{~cm}^{2}$ by $5 \mu \mathrm{m}$, and placed inside a $1.9 \mathrm{ml}$ sterile polypropylene tube. The microtome was cleaned with alcohol after each block had been cut, and a new blade was used. For dewaxing, $1 \mathrm{ml}$ of xylene (Aldrich) was added to each sample, and the tubes were placed on an automatic roller for 30 minutes. After five minutes of centrifugation at high speed (MSE Micro Centaur), the xylene was decanted, taking care not to lose the pellet of tissue. The xylene wash was repeated once, and $1 \mathrm{ml}$ of absolute ethanol was added to remove the xylene. After one minute of manual agitation, the tubes were centrifuged and the ethanol decanted. This was repeated once and the ethanol allowed to evaporate at room temperature overnight.

The desiccated tissue was digested at $37^{\circ} \mathrm{C}$ overnight with proteinase $\mathrm{K}$ (from Tritirachium album, Boehringer Mannheim) at a final concentration of $20 \mathrm{mg}$ per $\mathrm{ml}$ in $200 \mu \mathrm{l}$ digestion buffer consisting of TRIS $50 \mathrm{mM}$ (Boehringer Mannheim), EDTA $1 \mathrm{mM}$ (Sigma), and Tween $200.5 \%$ (Sigma). The proteinase $\mathrm{K}$ was denatured by heating to $94^{\circ} \mathrm{C}$ for 10 minutes and frozen at $-80^{\circ} \mathrm{C}$.

Cervical smear samples were prepared as described by Bauer et al, ${ }^{25}$ by vortexing the tip of the spatulum in saline for five minutes. The cell suspension is spun for five minutes at low speed and the supernatant fluid discarded. The pellet of cells is resuspended and digested with proteinase $K$ as for formalin fixed samples above. 


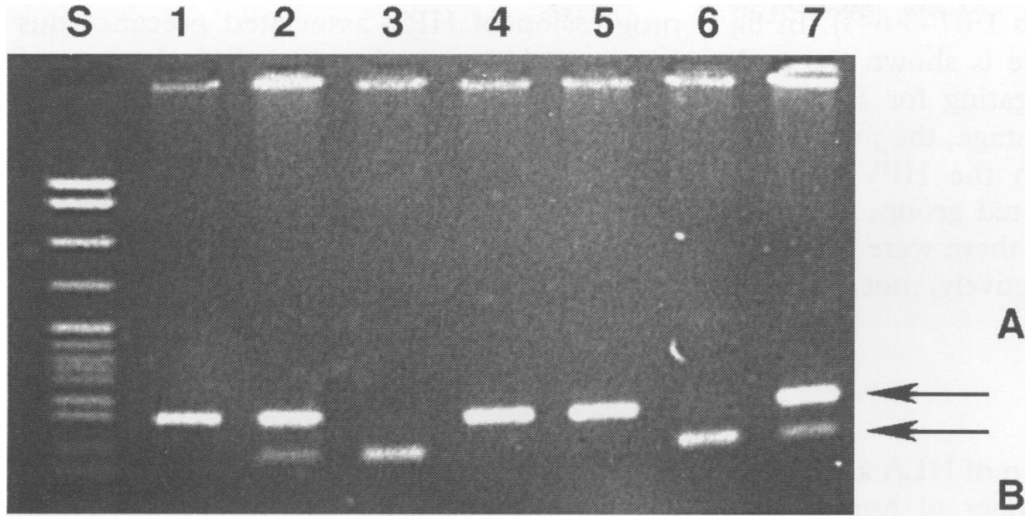

Figure 2 Agarose gel electrophoresis of $D Q$ amplified products after digestion with MluI. Lane S: molecular weight marker ( $p B R 322$ cut with MspI). Lanes 1, 2, and 3: control samples known to be from a non-DQw3 homozygote, a DQw3/non-DQw3 heterozygote, and a DQw3 homozygote, respectively. Lanes 4, 5, 6, and 7: unknown samples typed as non-DQw3 homozygote (lane 4), non-DQw3 homozygote (lane 5), $D Q w 3$ homozygote (ane 6), and DQw3/non-DQw3 heterozygote (lane 7), respectively. Arrow A indicates the position of the uncut and arrow $B$ indicates the position of the cut $D Q$ product.
The sensitivity of the system was measured by analysing dilutions of $\mathrm{SiHa}$ cells (containing one copy of HPV 16 per cell) in a constant background of $1 \mu \mathrm{g} / \mathrm{ml}$ ( $1 \mathrm{ng}$ in each $1 \mu \mathrm{ldot}$ ) carrier (sheared herring sperm DNA) in the same way as cervical smears.

The data were analysed using $\chi^{2}$ analysis and Yates's correction unless otherwise stated, ${ }^{26}$ and by calculating relative risks with the $95 \%$ confidence intervals. ${ }^{27}$

\section{Results}

Digestion of DQ amplified products with MluI produced restriction patterns (fig 2) which were specific for the three possible DQw3 types (null, heterozygous, and homozygous). There was complete concordance between our DQw3 typing results and the known DQ status of 32 samples previously typed using sequence specific oligonucleotide hybridisation. ${ }^{20}$

Successful amplification and typing for DQw3 was obtained in 149 cervical smears, 28 SCCC samples, and in 55 normal controls. No PCR products were produced in a small proportion of patient samples and this was consistent with our previous experience on the amplification of archival material. ${ }^{28}$ Figure 2 shows a representative HLA DQw3 typing result. The restriction pattern permits clear identification of DQw3 states of samples. Thirty of the $55(54.6 \%)$ normal controls were HLA DQw3 (25 heterozygous, five homozygous).

The table shows the histological diagnosis of the cervical samples and the HLA DQw3 prevalence for each histological stage. The prevalence of HLA DQw3 shows a modest rise in SCCC $(64.3 \%)$ compared with the group with normal histology $(53 \cdot 2 \%)$, but this was not significant $\left(\chi^{2}\right.$ of 0.96 without Yates's correction, and a relative risk of $1.58(95 \%$ confidence intervals $0.63-3 \cdot 96)$ ).

From the sensitivity titration, $10 \mathrm{SiHa}$ cells, equivalent to 10 copies of HPV 16 , could be consistently detected in a DNA dilution equivalent to 100000 cells.

Successful amplification and typing for HPV was carried out in 160 cervical smears and 28 SCCC samples. The table also shows the prevalence of HPV infection at the different histological stages. As previously reported, ${ }^{12}$ the prevalence of HPV increases with increasing dysplasia. Only three of the $165 \mathrm{HPV}$ positive cases contained the "low risk" HPV (6/11), and all three had normal histology; the remainder were either HPV 16, 18,31 , or 33 .

HLA DQw3 typing was available for 95 of the $102 \mathrm{HPV}$ positive and 78 of the $86 \mathrm{HPV}$ negative samples. When the prevalence of HLA DQw3 was analysed on the basis of HPV infection, rather than histology, 63 of 95 $(66.3 \%)$ of the HPV positive samples were HLA DQw3 (48 heterozygous, 15 homozygous), compared with 39 of $78(50.0 \%)$ of the HPV negative samples (24 heterozygous, 15 homozygous). This is a significant difference $\left(\chi^{2}\right.$ of $4.06 ; p<0.05$, relative risk of 1.97
Target material for PCR was either $1 \mu \mathrm{g}$ of
extracted genomic DNA from peripheral blood, or $10 \mu \mathrm{l}$ proteinase $\mathrm{K}$ digested archival cervical paraffin wax embedded tissue, and

HPV typing was carried out using a modifi450 base pair segment of the L1 gene was amplified using degenerate consensus to nitrocellulose and hybridised with the folsus probes which detect a wide range of HPV types; (ii) individual PCR generated 410 base individually; oligonucleotide probes specific HPV specific by increasing washing gency until only the appropriate plasmid positive controls, reactions carried out in th ans as negative controls, amplification with a pair of $\beta$-globin primer as amplification controls.

Figure 3 Prevalence of
$H L A D Q w 3$ in different histological stages (normal, and SCCC), segregated for of subjects contributing to each point on the graph is indicated. For all histological stages, the prevalence of $D Q w 3$ is greater in HPV positive samples, compared with ormal histology.
}

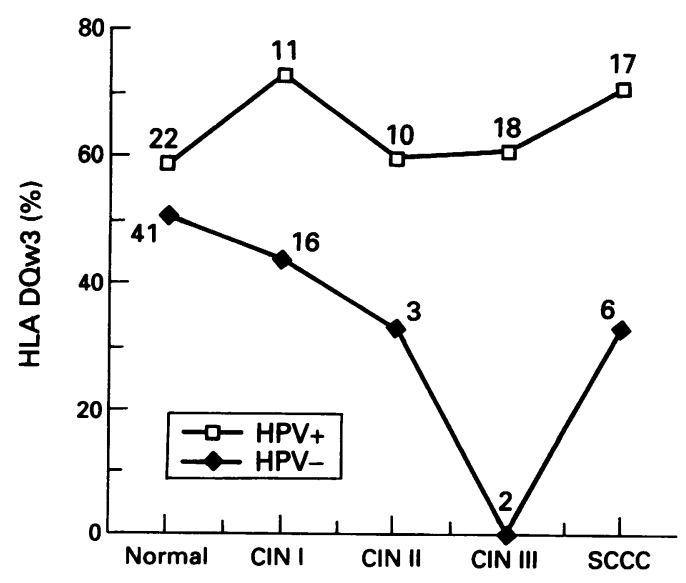


(95\% confidence intervals $1 \cdot 07-3 \cdot 64)$ ). In fig 3 HLA DQw3 prevalence is shown for each histological group, segregating for HPV status. At every histological stage, the prevalence of DQw3 was greater in the HPV positive group than the non-infected group, although for CIN III and SCCC, there were only one and two subjects, respectively, not infected with HPV.

\section{Discussion}

Skewing in the distribution of HLA alleles has been reported for a number of human diseases. ${ }^{29}$ Most of these diseases are described as "autoimmune", but associations between HLA alleles and human cancers, although rare, have been reported for Hodgkin's lymphoma, nasopharyngeal cancer, thyroid cancer, ${ }^{19}$ and most recently SCCC. ${ }^{17}$ The effect of other pathogenetic factors, particularly HPV infection, in the observed HLA association with SCCC is, however, not known.

This is the first study, as far as is known, to examine the full spectrum of cervical histology, from normal to invasive cancer, in relation to the presence of HPV subtypes and HLA DQw3. Our task was simplified by the development of a powerful and robust method for DQw3 typing based on primer mediated mutagenesis. This method is rapid and completely non-isotopic. The DQw3 typing results are complemented by HPV typing data. Our aim was to establish what role, if any, infection with HPV has in the association between DQw3 and SCCC. Our results show that there is a non-significant increase in DQw3 in patients with SCCC compared with women with normal cervical histology. However, there is a strong association between DQw3 and HPV which suggests that increases in DQw3 seen in women with SCCC are due to the overrepresentation of HPV positive women.

Two studies using genotyping, from Norway $^{32}$ and England, ${ }^{33}$ confirmed the association of DQw3 with SCCC and CIN III, respectively; one study from England using serotyping failed to find such an association. ${ }^{34}$ Vandenvelde et al studied both DQw3 and HPV, using molecular techniques in Belgian subjects, with histological results ranging from normal to carcinoma in situ, but without invasive SCCC. ${ }^{34}$ An association between DQw3 and carcinoma in situ was not found, but there was a significant increase in DQw3 in women with CIN I and CIN II, compared with normal controls. There was also no significant difference in the prevalence of DQw3, with respect to HPV. However, HPV status was only compared with women with normal histology. No comparison was made between the prevalence of DQw3 in HPV positive and negative subjects with the same histology. As fig 3 shows, there was very little difference in the prevalence of DQw3, based on HPV status in subjects with normal histology, but more so with increasing cervical dysplasia.

A number of lines of evidence suggest that the immune system has a role in limiting the progression of HPV associated precancerous lesions and in controlling the clinical course of HPV infection. Infiltrates of lymphocytes and macrophages in precancerous lesions ${ }^{35} 36$ suggest a role for cytotoxic $T$ lymphocytes and cytokines in reducing cell proliferation. Furthermore, people who are immunosuppressed, from a variety of causes, when exposed to HPV develop extensive and persistent infections. ${ }^{3738}$ The ability of polymorphisms at the HLA DQ loci to modify such immune responses to papillomaviruses is supported by the experimental infection of New Zealand rabbits with the Shope cottontail rabbit papillomavirus. ${ }^{39}$ All the animals developed papillomas which subsequently either regressed or developed into invasive carcinomas. A polymorphism of the DQ $a$ locus was associated with the development of invasive carcinoma, providing a relative risk of $4 \cdot 45$. The association between such polymorphisms in rabbits and the known human $D Q$ alleles is not clear at present, but comparative studies at a molecular level may identify major histocompatibility complex sequence motifs which are important in producing this increased susceptibility to HPV associated cervical cancer.

Many people are repeatedly exposed to infection with HPV, and most eradicate such infections. ${ }^{16}$ The observed increase in the prevalence of DQw3 in HPV infected subjects is probably because of the relative inability of those with DQw3 alleles to clear HPV infection. Each infection will therefore result in a longer than average period of HPV persistence, and DQw3 subjects will be overrepresented in the subpopulation with HPV infection. The prevalence of DQw3 in a HPV infected subpopulation will increase with the duration of infection, and will therefore be greater in a subpopulation with longstanding HPV infection, compared with recent HPV infection. Progression from CIN I to SCCC takes a number of years, and the CIN II, CIN III, and SCCC groups represent populations with chronic HPV infection. ${ }^{36}$

The association of a HLA allele with a disease phenotype is often explained by the ability of the associated allele to present immunogenic peptides with greater efficiency than the alternative alleles in the population. This has been best characterised for cerebral malaria, where the presence of HLAB53 is associated with a milder clinical course, and an HLAB53 restricted cytotoxic $T$ cell response to malarial antigens has been demonstrated..$^{40}$ This mechanism explains how a HLA molecule may confer the ability to clear an infection, but cannot explain how DQw3 confers an inability to clear HPV infection. HLA molecules, however, present antigens not only for the final effector pathways of the immune response, but also during the development of the immune system. In particular, during the induction of self-tolerance, deletion of $T$ cell clones in the thymus is determined by the recognition of self-peptides presented by HLA molecules. ${ }^{41}$ One explanation for our observed results is the deletion by people with the 
HLA DQw3 allele of $\mathrm{T}$ cell clones which are important for recognising HPV peptides.

In conclusion, subjects with DQw3 are overrepresented in the HPV infected population, suggesting that they are less likely to clear HPV infection. This, we believe, is an important factor in the overrepresentation of DQw3 in SCCC. Prospective studies on subjects with CIN I are required to establish whether HLA DQw3 typing can identify women most likely to benefit from cervical screening programmes.

WZM and Y-MDL are Wellcome Medical Graduate Fellows; $\mathrm{KO}$ is a Birthright Fellow. This work was supported by the Oxford Regional Health Authority.

1 Peto R. Introduction: geographical patterns and trends. In: Peto $\mathrm{R}$, zur Hausen $\mathrm{H}$, eds. Viral etiology of cervical cancer. Banbury Report No 21, Cold Spring Harbour, New Banbury Report No 21, Cold Spring Harbour, N

2 Reeves WC, Rawls WE, Brinton LA. Epidemiology of genital papillomaviruses and cervical cancer. Rev Infect Dis 1989;11:426-39.

3 Terris M, Wilson F, Smith H, Sprung E, Nelson JH Jr. The relationship of coitus to carcinoma of the cervix. Am f Public Health 1967;57:840-7.

4 Brinton LA, Hamman RF, Huggins GR, Lehman HF, Levine RS, Mallin K, et al. Sexual and reproductive risk factors for invasive squamous cell cervical cancer. $\mathcal{f}$ Natl factors for invasive squamo
Cancer Inst 1987;79:23-30.

5 Zunzunegui MV, King M-C, Coria CF, Charlet J. Male influences on cervical risk. Am $f$ Epidemiol 1986;123: 302-7.

$6 \mathrm{Li} \mathrm{J-Y,} \mathrm{Li} \mathrm{FP,} \mathrm{Blot} \mathrm{WJ,} \mathrm{Miller} \mathrm{RW,} \mathrm{Fraumeni} \mathrm{JF} \mathrm{Jr.}$ Correlation between cancers of the uterine cervix and penis in China. $\mathcal{F}$ Natl Cancer Inst 1982;69:1063-5.

7 Nahmias AJ, Naib ZM, Josey WE, Franklin E, Jenkins R. Prospective studies of the association of genital herpes simplex infection and cervical anaplasia. Cancer Res 1973;33:1491-7.

8 Vonka V, Kanka J, Hirsch I, Zavadova H, Kremar M, Suchankovo A, et al. Prospective study on the relationship between cervical neoplasia and herpes simplex typeship between cervical neoplasia and herpes simplex type2 virus. II. Herpes simplex type-2 antibody presence

sera taken at enrollment. Int $\mathcal{7}$ Cancer 1982;33:61-6.
9 Franceschi S, Doll R, Gallwey J, La Vecchia C, Peto R, Spriggs AI. Genital warts and cervical neoplasia: an epidemiological study. Br $\mathcal{F}$ Cancer 1983;48:621-8.

10 Cooper K, Herrington CS, Graham AK, Evans MF, McGee J O'D. In situ evidence for HPV 16, 18, 33 integration in cervical squamous cell cancer in Britain and South Africa. $\mathcal{F}$ Clin Pathol 1991;44:406-9.

11 Walboomers JMM, Melkert PWJ, van den Brule AJC, Snijders PJF, Meijer CILM. The polymerase chain reacSnijders PJF, Meijer CJLM. The polymerase chain reac-
tion for human papillomavirus screening in diagnostic tion for human papillomavirus screening in diagnostic cytopathology of the cervix. In: Herrington CS, McGee JO'D, eds. Diagnostic molecular pathology: a practical

2 Reid R, Greeberg M, Jenson B. Sexually transmitted papillomaviral infections. I. The anatomic distribution and pathological grade of neoplastic lesion associated with different viral types. Am 7 Obstet Gynecol 1987;156: 212-22.

13 Shirasawa H, Tomita Y, Kubota K, Kasai K, Sekiya S, Takamizawa $\mathrm{H}$, et al. Detection of human papillomavirus type 16 DNA and evidence for integration into mavirus type 16 DNA and evidence for integration into
the DNA in cervical dysplasia. $f$ Gen Virol $1986 ; 67$ : the DNA

14 Burk RD, Kadish AS, Calderin S, Romney SL. Human paillomavirus infection of the cervix detected by cervicovaginal lavage and molecular hybridisation: correlation with biopsy results and papanicolaou smear. Am $\mathcal{F}$ Obstet Gynecol 1986;154:982-9.
15 Tooran PG, Arrand JR, Wilson LP, Sharp DS. Human papillomavirus infection of the uterine cervix of women without cytological signs of neoplasia. $B M \mathcal{F} 1986 ; 293$. $1261-4$

16 Syrjanen K, Syrjanen S. Epidemiology of human papillomavirus infections and genital neoplasia. Scand $\mathcal{F}$ Infect Dis Suppl 1990;69:7-17.

17 Wank R, Thomssen C. High risk of squamous cell carcinoma of the cervix for women with HLA-DQw3. Nature noma of the cervix for wom
(Lond) 1991;352:723-5.

18 Braciale TJ, Braciale VL. Viral antigen presentation and MHC assembly. Semin Immunol 1992;4:81-4.

19 Panza N, Vecchio LD, Maio M, Felice MD, Lombardi G, Minozzi $\mathrm{M}$, et al. Strong association between an HLADR antigen and thyroid cancer. Tissue Antigens 1982;20 155-8.

20 Ferenczy A, Winkler B. Carcinoma and metastatic tumours of the cervix. In: Kurman RT, ed. Blaustein's pathology of the female genital tract. New York: Springer pathology of the female

21 Vandenvelde C, Foor MD, Beers DV. HLA-DOB1*03 and cervical intraepithelial neoplasia grades I-III. Lancet and cervical intraepi

22 Bugawan TL, Erlich HA. Rapid typing of HLA-DQB1 DNA polymorphisms using non-radioactive oligonucleotide probes and amplified DNA. Immunogenetics 1991;33:163-70.

23 Saiki RK, Gelfand DH, Stoffel S, Scharf SJ, Huguchi R, Horn GT, et al. Primer-directed enzymatic amplification of DNA with a thermostable DNA polymerase. Science 1988;239:487-91.

24 Sambrook J, Fritsch EF, Maniatis T. Isolation of DNA from Mammalian Cells: Protocol I. In: Sambrook J, Fritsch EF, Maniatis T, eds. Molecular cloning, a laboraFritsch EF, Maniatis T, eds. Molecular cloning, a labora-
tory manual. Vol 2. Cold Spring Harbor: Cold Spring Harbor Laboratory Press, 1989:9.16-9.19.

25 Bauer HM, Greer CE, Manos MM. Determination of genital human papillomavirus infection by consensus PCR amplification. In: Herrington CS, McGee JO'D eds. Diagnostic molecular pathology: a practical approach. Oxford: Oxford University Press, 1992:131-52.

26 Yates, F. Contingency tables involving small numbers and the $\chi^{2}$ test. $\mathcal{F}$ Royal Stat Soc 1934;(Suppl 1):217-35.

27 Altman DG. Comparing risks. In: Altman DG, ed. Practical statistics for medical research. London: Chapman Practical statistics for medica
and Hall, 1989:266-71.

28 An SF, Fleming KA. Removal of inhibitors(s) of the polymerase chain reaction from formalin fixed, paraffin wax embedded tissues. F Clin Pathol 1991;44:924-7.

29 Tiwari JL, Terasaki P, eds. Overview. In: HLA and disease associations. New York: Springer Verlag, 1989:32-49.

30 Tiwari JL, Terasaki $\mathrm{P}$, eds. Malignancy. In: HLA and disease associations. New York: Springer Verlag, 1985:277-322.

$31 \mathrm{Lu} \mathrm{S-J,} \mathrm{Day} \mathrm{NE,} \mathrm{Lepage} \mathrm{LDV,} \mathrm{Wang} \mathrm{PC,} \mathrm{Chan} \mathrm{SH,}$ Simons $\mathrm{M}$, et al. Linkage of a nasopharyngeal carcinoma susceptibility locus to the HLA region. Nature (Lond) susceptibility locus

32 Helland A, Borresen AL, Ronningen KS, Thorsby E. HLA antigens and cervical carcinoma. Nature (Lond) 1992; 356:23.

33 David ALM, Taylor GM, Gokhale D, Alpin JD, Seif MF Tindall VR, et al. HLA-DQB ${ }^{\star} 03$ and cervical intraepithelial neoplasia type III. Lancet. 1992;340:52.

34 Glew SS, Stern PL, Davidson JA, Dyer PA. HLA antigens and cervical carcinoma. Nature (Lond) 1992;356:22.

35 Coleman DV, Evans DMD, eds. Primary malignant epithelial tumours: classification and squamous cell carcinoma. In: Biopsy pathology and cytology of the cervix. cinoma. In: Biopsy pathology and cytology of

36 Tagami H, Aiba S, Rokugo M. Regression of flat warts and common warts. Clin Dermatol 1985;3:170-8.

37 Krogh GV, Rylander E. Immune response to papilloma infection. In: Syrjanen KL, Gissmann, Koss LG eds. Papilloma virus and human disease. New York: Springer-Verlag, 1987:334-71.

38 Palefsky J. Human papillomavirus infection among HIVinfected individuals. Implications for development of malignant tumors. Hematol Oncol Clin North Am 1991;5: m57-70.

39 Han R, Breitburd F, Marche PN, Orth G. Linkage of regression and malignant conversion of rabbit viral papillomas to MHC class II genes. Nature (Lond) 1992;356:66-8.

40 Hill AVS, Elvin J, Willis AC, Aidoo M, Allsopp CEM, Gotch FM, et al. Molecular analysis of the association of HLA-B53 and resistance to severe malaria. Nature (Lond) 1992;360:434-9.

41 Lo D. T-cell tolerance. Curr Opin Immunol 1992;4:711-5. 